\title{
Comparison of Inorganic and Organic Matter Sedimentation in a Natural Laboratory: A One-Year Study at Lough Hyne Marine Reserve, Ireland
}

\author{
Stefanie Broszeit, ${ }^{1}$ John Davenport, ${ }^{1}$ Mark Jessopp, ${ }^{2}$ Luke Harman, ${ }^{1}$ and Rob McAllen ${ }^{1}$ \\ ${ }^{1}$ School of Biology, Ecology and Earth Sciences, University College Cork, Distillery Fields, North Mall, Cork, Ireland \\ ${ }^{2}$ Coastal \& Marine Research Centre, University College Cork, Irish Naval Base, Haulbowline, Cork, Ireland
}

Correspondence should be addressed to Stefanie Broszeit, stefbroszeit@gmail.com

Received 27 July 2012; Accepted 9 October 2012

Academic Editor: Jakov Dulčić

Copyright (C) 2012 Stefanie Broszeit et al. This is an open access article distributed under the Creative Commons Attribution License, which permits unrestricted use, distribution, and reproduction in any medium, provided the original work is properly cited.

\begin{abstract}
Measuring sedimentation rates may provide useful information on the habitat preferences of marine organisms. To understand the effect of flow rates and meteorological conditions on sedimentation in the absence of other confounding factors, sedimentation of organic (OM) and inorganic (IOM) matters was measured at 6 sites in Lough Hyne Marine Reserve (a semienclosed marine lake) over the course of 13 months. During winter, both OM and IOM were imported to the Lough, peaking in December at Whirlpool, the site nearest to the Lough entrance, likely as a result of extreme weather conditions causing resuspension of matter outside the Lough. Highest inorganic matter (IOM) sedimentation occurred in December $\left(47.36 \mathrm{gm}^{-2} \mathrm{~d}^{-1}\right.$ at Whirlpool Cliff) and was related to November wind speeds $\left(R^{2}=0.39, P<0.001\right)$. Decreasing current speed also caused a decline in IOM sedimentation. Highest OM sedimentation occurred in December at Whirlpool $\left(5.59 \mathrm{gm}^{-2} \mathrm{~d}^{-1}\right)$, but was not related to meteorological conditions. No single environmental factor strongly influenced organic matter (OM) sedimentation. One-way ANOVAs on OM and logtransformed IOM data showed that sedimentation differed significantly amongst the six sites within the Lough. Increased plankton production in the Lough during summer led to increased OM sedimentation in areas of low current speed away from the entrance of the Lough.
\end{abstract}

\section{Introduction}

The settlement of matter out of the water column onto the seafloor is an important process for benthic fauna. Sinking organic matter provides a high-quality food source for marine benthic communities which, except where light can still penetrate and benthic photosynthesis occur, are dependent on surface water production for energy input [1]. Sedimentation rates are largely influenced by the availability of nutrients in the surface water and by seasonality, which influences plankton growth. Dying phytoplankton blooms provide massive sedimentation events in short periods with a marked seasonality [2], at least at medium and high latitudes. However, benthic communities can be adversely affected by high organic matter input as described by classic models [3]: an increase of organic materials at first causes an increase in benthic biomass and microbial metabolism, but eventually this leads to the complete depletion of oxygen. The consequences of anoxia in the benthic habitat and the overlying water column are massive die-off events in the benthic community [4]. Additionally, areas of low water exchange, such as semi-enclosed bays and fjords, are known to develop temporal or permanent stratification of the water column. This is usually due to reduction of current speed by narrow and shallow inlets. The stratification worsens the hypoxic situation as it inhibits exchange of water across the thermocline. Seasonal or longer term anoxia is a well-studied consequence of stratification and organic enrichment [5].

Inorganic material such as gravel and sand will settle in areas exposed to strong hydrographic forces such as subtidal currents and wind-driven waves [6]. Finer particles remain in suspension longer and settle when the water velocity has fallen to a threshold value. Fine muds and silt settle in areas of low current velocity and here organic matter also 
settles out. Benthic animals choose their habitat according to factors such as current flow, grain size, stability, and organic matter content. Because of negligible sedimentation of organic matter in high-energy areas, and the danger of being dislodged, few animals live in these sediments, notable exceptions being venerid bivalve molluscs.

Lough Hyne (Lough Ine) on the SW coast of Ireland is a semi-enclosed fully marine lake that provides a natural laboratory for the study of the interactions of sedimentation and environmental factors. It is connected to the nearby Atlantic by a shallow, narrow channel (the "Rapids") about $12 \mathrm{~m}$ wide (Figure 1 ) and between $1 \mathrm{~m}$ at ebb and at most $4 \mathrm{~m}$ deep at high tide. Due to this narrow inlet, the Lough exhibits a range of flow regimes from fast at the Rapids (up to $3 \mathrm{~m} \mathrm{~s}^{-1}$ ) to virtually still water $\left(<0.001 \mathrm{~m} \mathrm{~s}^{-1}\right)$ in the North Basin. Freshwater influx is negligible [7] and salinity falls within the range of marine waters, resulting in the Lough's flora and fauna being typically marine. Roughly speaking, the Lough can be divided into three parts: the South Basin and North Basin are approximately $20 \mathrm{~m}$ in depth and are divided from each other by Castle Island. The two basins are connected by the Western Trough, with a maximum depth of $48 \mathrm{~m}$ [8]. Lough Hyne is an ideal site to study coastal oceanographic processes as it is sheltered, comparatively shallow, and exhibits a wide range of flow rates within a relatively small area [9]. Within this body of water, the effects of current speed can be studied in the absence of (or much reduced) other confounding factors such as large distances between sampling sites or sampling across biologically and oceanographically different bodies of water. Weather conditions are constant across the entire study area due to their small size, while previous studies have shown no significant spatial variation in either water chemistry (Total N, Total P, silicates) [10], or other factors likely to influence sedimentation in different areas of the Lough such as phytoplankton [10], and zooplankton abundance [11]. In addition, because it is a marine reserve, anthropogenic disturbances such as dredging and trawling do not take place, and therefore resuspension of sediments due to these processes cannot impact the results.

Only limited work has been carried out previously on sedimentation within the Lough. Bell and Barnes [12] focused on sedimentation onto rocky substrates to study environmental conditions for encrusting sponges. They found that for IOM, rates were higher in winter than summer months, while sedimentation of OM was higher in the summer than winter. Interestingly, sedimentation was highest in areas of intermediate current speed such as Southwest, Goleen, and cliff faces of the Western Trough.

The research reported here was designed to address the following questions.

(a) How is sedimentation of organic and inorganic material distributed within the Lough and how does this change over time?

(b) How do oceanographic and meteorological factors influence sedimentation rates?

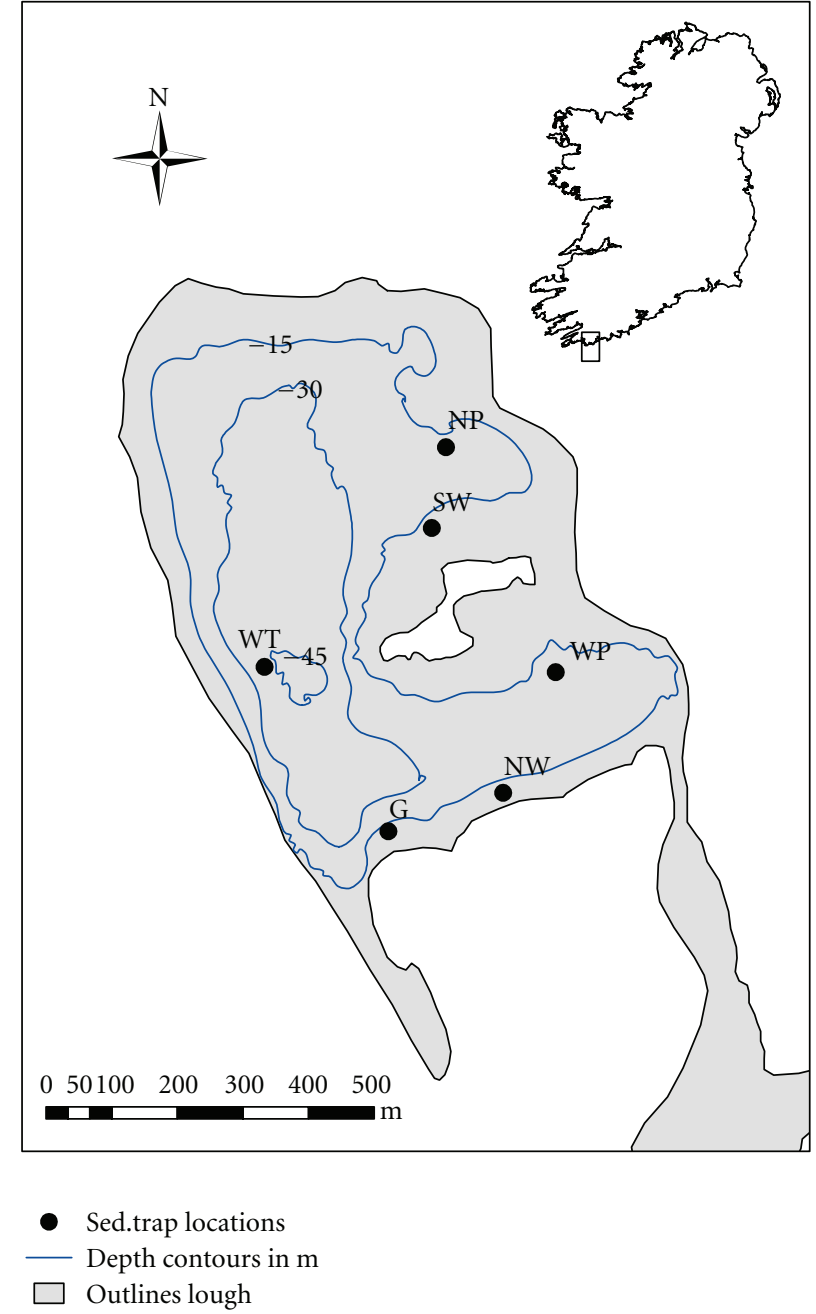

Figure 1: Sediment trap locations for the 13-month survey of Lough Hyne from June 2009 to July 2010. G: Goleen, NP: North Pier, NW: Northwest, SW: Southwest, WP: Whirlpool, WT: Western Trough.

\section{Materials and Methods}

2.1. Design and Deployment of Sediment Traps. Sediment traps were deployed at six sites around Lough Hyne (Figure 1). Sites were chosen to reflect different localities and current speeds (based on previous studies) in the Lough ranging from fast $\left(0.24 \mathrm{~m} \mathrm{~s}^{-1}\right)$ near Whirlpool Cliff to slow $\left(0.02 \mathrm{~m} \mathrm{~s}^{-1}\right)$ in the northern part of the Lough. A $10 \mathrm{~kg}$ block of cement was used to anchor a rope in each location, and a surface buoy ensured that the rope was taut during the duration of the study. A sediment trap holder with six spaces for individual traps was suspended at a depth of $10 \mathrm{~m}$ from the surface buoy (Figure 2). A depth of $10 \mathrm{~m}$ was chosen to avoid measuring resuspension from the sea floor.

Each trap was made of ABS drain pipe with an inner diameter of $45 \mathrm{~mm}$ and a length of $300 \mathrm{~mm}$, sealed at the lower end with an ABS disc. The traps had an aspect ratio (width to height) of $1: 6.67$. This is above the recommended 


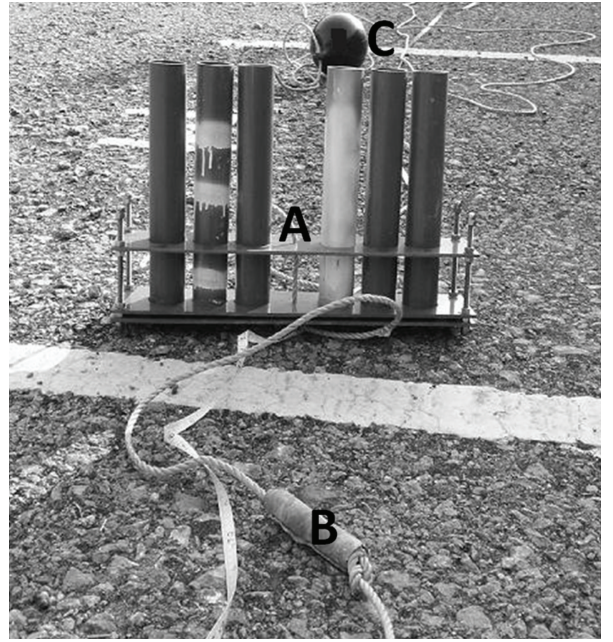

Figure 2: Six sediment traps in trap holder (A). A lead weight (B) rolled around the rope held the traps vertical in the water column. The surface buoy $(\mathrm{C})$ ensured that the trap was suspended at the correct depth. Markings on the traps helped the divers to choose the correct trap on a given sampling occasion. The white trap remained in the holder throughout, purely for balance. The striped trap was the control.

minimum of $1: 3$, while the diameter exceeded the recommended minimum of $40 \mathrm{~mm}$ [13]. Four replicate traps in each carrier were filled to a depth of $70 \mathrm{~mm}$ with a $5 \%$ formalin/brine solution of 100 psu salinity. Formalin preserved the organic material within the falling sediment, while the brine was necessary to achieve a dense layer in which the sediments would remain without re-suspension [14]. Four tubes per site and month were chosen in case tubes were lost during the sampling interval and replication helped to confirm the representative nature of the collected data in relation to each site and month. A fifth trap was filled with seawater as a control. This control was only used to test the necessity of use of formalin for the monthly time span used, and data from the control tubes were omitted in the final analysis. A sixth trap in each holder was necessary for balance and was not removed during the course of the experiment. Traps were deployed and collected by SCUBA divers at intervals of approximately 4 weeks. Traps were sealed with drain pipe lids before removal from the trap holder and brought to the surface in a carrier in order to ensure the least possible disturbance to the trapped sediment. Each lid had a hole of $2 \mathrm{~mm}$ diameter drilled in the top to allow for pressure equalisation during the diving operations. After a pilot study to test functionality of the trap design, data collection was started in June 2009 and continued until July 2010.

2.2. Sediment Analysis. In the laboratory, each trap was shaken vigorously to resuspend the deposited material. A subsample of $55 \mathrm{~mL}$ was gently filtered through a preweighed $47 \mathrm{~mm}$ GF/C Whatman glass fibre filter using a KNF Neuberger Laboport vacuum pump. This was followed by a $50 \mathrm{~mL}$ wash of distilled water to remove salt [13]. Filters were dried in an oven at $80^{\circ} \mathrm{C}$ overnight, weighed, and ashed at $450^{\circ} \mathrm{C}$ for $6 \mathrm{~h}$ in a muffle furnace to remove organic matter before being reweighed. Sedimentation rates were calculated as g sediment $\mathrm{m}^{-2} \mathrm{~d}^{-1}$ for both organic and inorganic fractions.

2.3. Collection of Factorial Data for Analysis. Current speed was measured using a Nortek Acoustic Doppler Velocimeter which was suspended vertically from a surface buoy anchored to the bottom by a $10 \mathrm{~kg}$ cement weight. Recording of current speed was conducted from January to March 2011 to ensure that resuspension of sediment during equipment deployment and retrieval did not have any effect on sedimentation rates during the experiment. The velocimeter was not available after completion of the sediment trap sampling and therefore current speed was measured in spring of 2011. To reduce interference due to the presence of the anchor rope, the velocimeter was placed in a steel frame that held it $50 \mathrm{~cm}$ away from the rope. A counterweight ensured upright position of the velocimeter during deployments. Using GPS, the velocimeter was placed at the same locations where the sediment trap holders had been previously held and left to collect data for two weeks at each location. Current speeds were measured at a depth of $5 \mathrm{~m}$, halfway between the surface and the depth at which the sediment traps had been suspended. Data were divided into current speeds at spring inflow, spring outflow, neap inflow and neap outflow, and mean maximum current speeds in each of these four categories subsequently used for analysis. Weather data were obtained from Met Éireann and consisted of mean hourly wind speeds (knots) for each month from the M3 weather buoy $\left(\mathrm{N} 51^{\circ} 13^{\prime} 0^{\prime \prime}\right.$, W10 $\left.33^{\prime} 0^{\prime \prime}\right)$, near Mizen Head, County Cork, and rainfall $(\mathrm{mm})$ per month at Valentia weather station, County Kerry. The distance from the M3 weather buoy to the Lough is approximately $90 \mathrm{~km}$, while distance from the Valentia weather station to the Lough is approximately $85 \mathrm{~km}$. Temperature was recorded at 30 min intervals in the South Basin. A Hobo Pro v.2 water temperature data logger (Onset Computer Corporation) was suspended from a mooring buoy at a depth of $5 \mathrm{~m}$ and logged temperature continuously throughout the study period. Distance to the Rapids was measured using the Path tool in Google Earth. For each site, a line was drawn from the inner mouth of the Rapids through the South Basin to the southern trap locations (marked using GPS data). For the two northern sites, two routes were measured: one moving east to west along the South Basin to the centre of the Western Trough, then northward and finally in an eastern direction north of Castle Island to the trap location. For a second set of measurements, a path was chosen that passed directly through the narrows between Castle Island and the East Shore to the trap location.

\section{Results}

3.1. Data Exploration. Data showed equal variances (Cochrane's test) for organic matter sedimentation (OM) while inorganic matter sedimentation (IOM) had equal variance only after $\log _{10}$ transformation. Current speed and distance from Rapids were collinear, rainfall and wind data also, so 


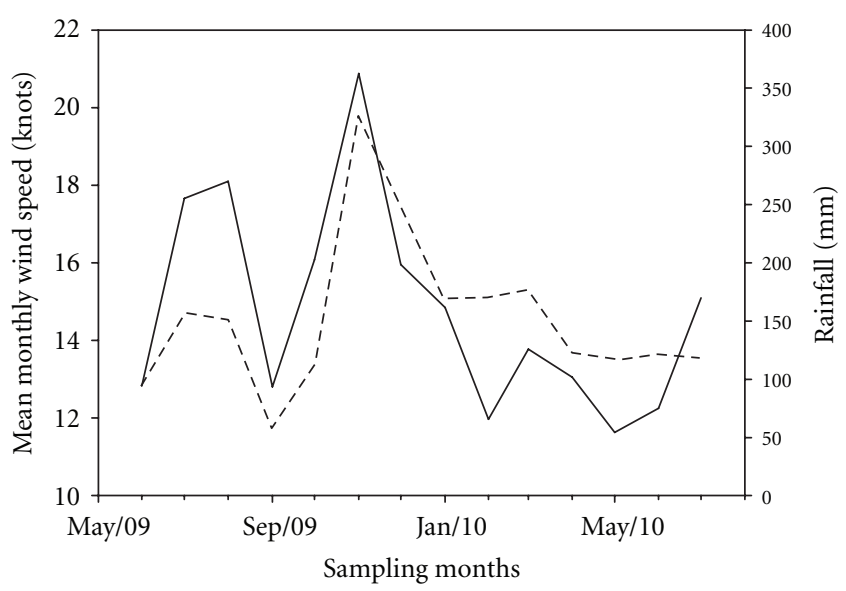

FIgURE 3: Mean hourly wind speed in knots recorded at the Irish M3 weather buoy (dashed line), and monthly rainfall at the Valentia recording station (solid line). Data courtesy of Met Éireann.

multiple regression analyses were not performed. Multiple linear regression was not performed on the data set as weather data were not collected at each individual sampling station and current speed was only measured once at each site, rather than continuously throughout the study period.

3.2. Environmental Factors. Mean hourly wind speed (knots) and rainfall $(\mathrm{mm})$ are graphically displayed in Figure 3. Lowest mean wind speed occurred in September 2009 (11.7 knots) and highest mean wind speed was recorded in November 2009 (19.8 knots). Highest rainfall was recorded in November 2009 with $362.8 \mathrm{~mm}$, while lowest rainfall in the study period occurred in May $2010(54.2 \mathrm{~mm})$.

Highest mean maximum current speed was recorded at Whirlpool during spring inflow $\left(0.24 \mathrm{~m} \mathrm{~s}^{-1}\right)$ and lowest at Northwest during spring inflow $\left(0.02 \mathrm{~m} \mathrm{~s}^{-1}\right)$ (Figure 4). Currents at North Pier were faster than at Northwest, indicating that there was tidal flow through the gap between the East shore and Castle Island.

3.3. Distribution of Sedimentation in the Lough. IOM sedimentation rates ranged from $1.67 \mathrm{~g} \mathrm{~m}^{-2}$ day $^{-1}$ at Northwest in September to $47.37 \mathrm{~g} \mathrm{~m}^{-2}$ day $^{-1}$ at Whirlpool in December. OM ranged from $0.97 \mathrm{~g} \mathrm{~m}^{-2}$ day $^{-1}$ at North Pier in January to $5.60 \mathrm{~g} \mathrm{~m}^{-2}$ day $^{-1}$ at Whirlpool in December. Figure 5 shows IOM and OM sedimentation for each site over 13 months. Most noteworthy is a peak in IOM in December, particularly at the sites close to the entrance of the Lough, highest sedimentation being recorded at Whirlpool, followed by Southwest, then Goleen and Western Trough. Sedimentation rates at the two northern sites (Northwest and North Pier) show an increase in IOM over the winter months (November to February), but not featuring such pronounced peaks as the southern sites in December. Similarly, a peak of OM occurred in December at Whirlpool Cliff and also to a lesser extent at Southwest and Goleen, but this pattern was not apparent in the data for the Western Trough, Northwest, and North Pier.

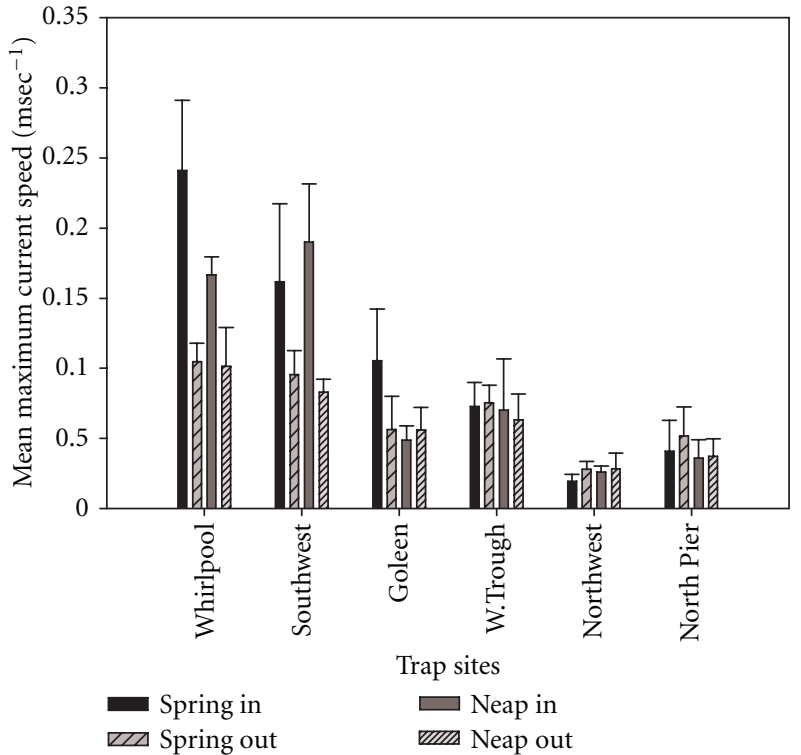

Figure 4: Mean maximum current speed of four tidal states (spring inflow, spring out flow, neap inflow, and neap outflow) at each sediment trap site in Lough Hyne Marine Reserve. Error bars indicate standard deviation. Data were collected at each site over a spring and neap cycle from January to March 2011.

TABLe 1: Post-hoc Tukey procedure to test at which sites sedimentation differed to a significant degree in Lough Hyne during the study period.

(a) IOM sedimentation

\begin{tabular}{lccccc}
\hline \multicolumn{5}{c}{ Whirlpool } & Southwest \\
\hline Southwest & $*$ & & & & \\
Goleen & $*$ & NS & & & \\
W. trough & $*$ & $*$ & NS & & \\
Northwest & $*$ & $*$ & $*$ & NS & \\
North Pier & $*$ & $*$ & $*$ & $*$ & NS \\
\hline
\end{tabular}

(b) OM sedimentation

Whirlpool Southwest Goleen W. trough Northwest

Southwest NS

Goleen $\quad * \quad$ NS

W. trough NS NS NS

Northwest $\quad * \quad$ NS NS NS

$\begin{array}{lllll}\text { North Pier } & * & \text { NS } & \text { NS } & \text { NS }\end{array}$

NS: not significant, ${ }^{*}$ : significant: $P<0.05$.

A one-way ANOVA on log-transformed IOM data showed that IOM sedimentation rate was significantly different amongst sites $(F=24.82, d f=5, P<0.001)$. Posthoc Tukeys pairwise comparisons showed that most pairs exhibited statistically significant differences (Table 1(a)). Only four pairs did not; in each case they were sites adjacent to one another: Southwest-Goleen, Goleen-Western Trough, Western Trough-Northwest and Northwest-North Pier. 


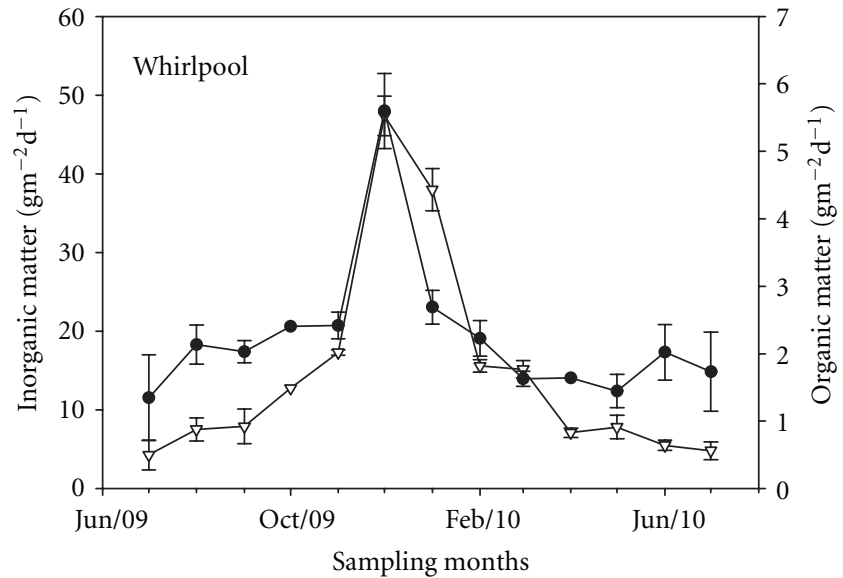

(a)

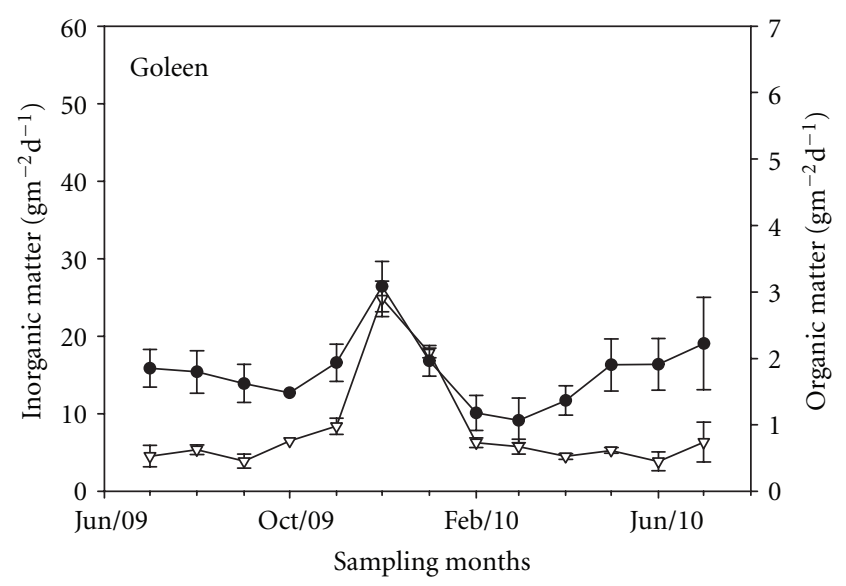

(c)

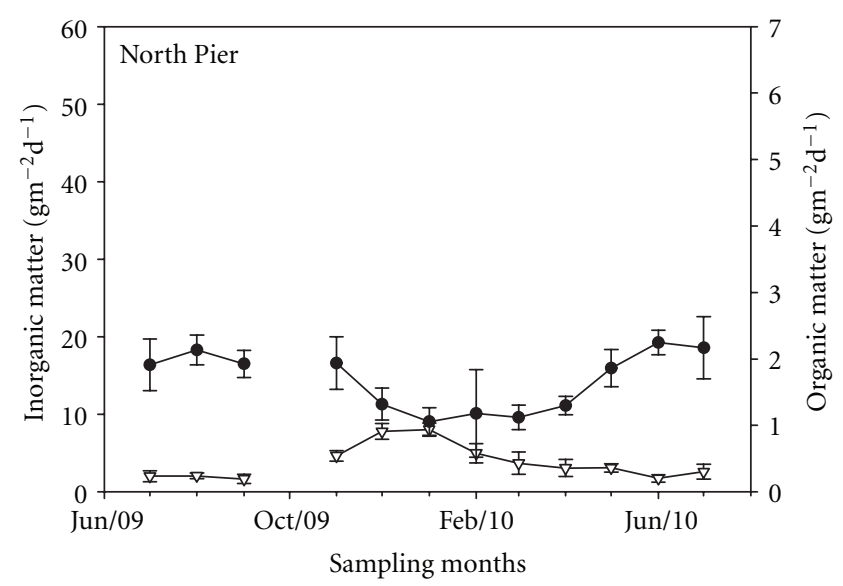

(e)

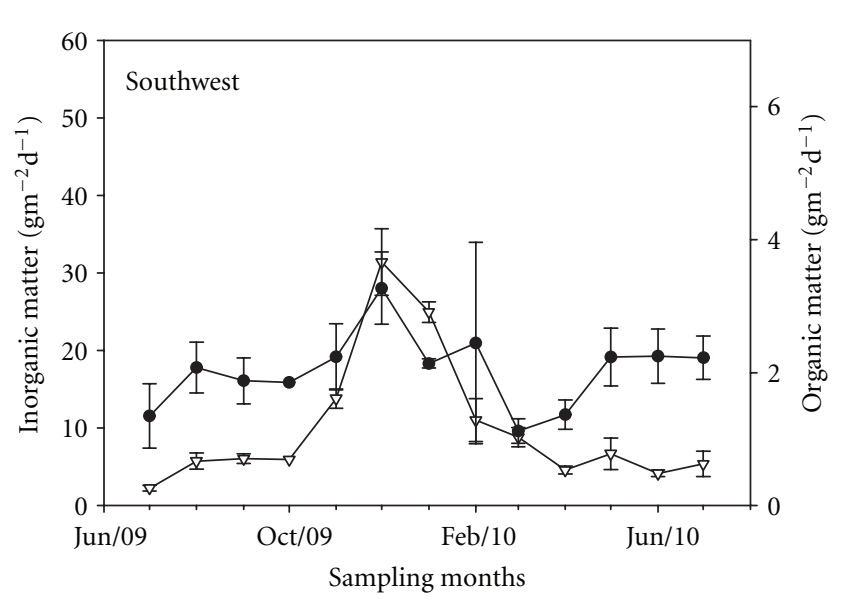

(b)

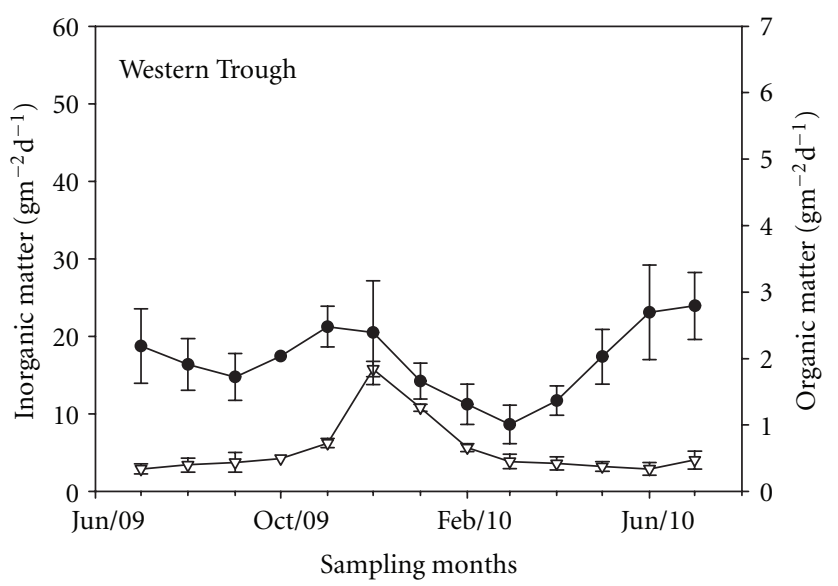

(d)

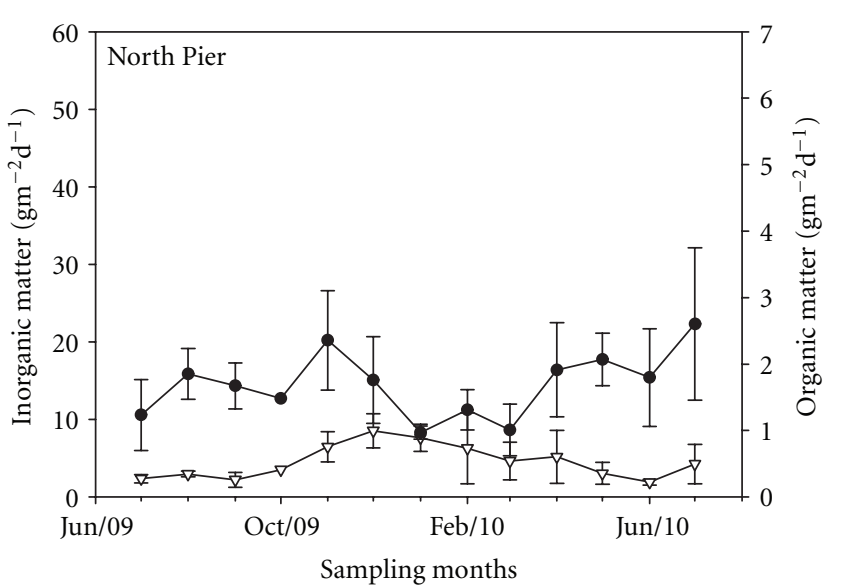

(f)

FIgURE 5: Sedimentation rates at six sites in Lough Hyne over the course of the study period; $(\nabla)$ : inorganic matter sedimentation, $(\bullet)$ : organic matter sedimentation. Error bars indicate standard deviation. Most October samples were lost by accident. However, one sample from each site (except Northwest) remained for analysis. 
TAble 2: $R^{2}$-values and related $P$-values for linear regressions performed to explore which 370 environmental conditions had an influence on inorganic and organic matter sedimentation 371 rates in Lough Hyne during the study period.

\begin{tabular}{lcccc}
\hline Factor & \multicolumn{2}{c}{ Inorganic } & \multicolumn{2}{c}{ Organic } \\
& $R^{2}$ & $P$ & $R^{2}$ & $P$ \\
\hline Weather & & & & \\
Wind speed previous month (knots) & $0.39<0.001$ & 0.04 & 0.001 \\
Rainfall previous month (mm) & $0.21<0.001$ & $0.09<0.001$ \\
Wind speed same month (knots) & $0.15<0.001$ & 0.04 & 0.001 \\
Rainfall same month (mm) & 0.02 & 0.023 & 0.04 & 0.001 \\
\hline Distance & & & & \\
Long route to North Basin (m) & $0.17<0.001$ & 0.4 & 0.001 \\
Short route to North Basin (m) & $0.17<0.001$ & 0.6 & $<0.001$ \\
\hline Current speed & & & & \\
Spring inwards $\left(\mathrm{ms}^{-1}\right)$ & $0.22<0.001$ & $0.07<0.001$ \\
Spring outwards $\left(\mathrm{ms}^{-1}\right)$ & $0.16<0.001$ & $0.07<0.001$ \\
Neap inwards $\left(\mathrm{ms}^{-1}\right)$ & $0.15<0.001$ & $0.06<0.001$ \\
Neap outwards $\left(\mathrm{ms}^{-1}\right)$ & $0.19<0.001$ & $0.07<0.001$ \\
\hline
\end{tabular}

For OM data (untransformed), sites also differed significantly (one-way ANOVA, $F=4.62, d f=5, P<0.001$ ). Most pairwise comparisons were nonsignificant (Table 1(b)); the only exceptions were between Whirlpool and other locations within the Lough (Whirlpool-Goleen, WhirlpoolNorthwest, and Whirlpool-North Pier).

\subsection{Effects of Environmental Conditions on Sedimentation.} Linear regression showed that, for IOM, wind speed during the previous month yielded the highest $R^{2}$ value $\left(R^{2}=0.39\right.$, $P<0.001$ ) of all environmental factors studied (Table 2). All other factors had lower $R^{2}$ values, though all relationships were statistically significant $(P<0.05)$. For $\mathrm{OM}$, no single environmental factor had a particularly strong influence, and $R^{2}$ values were low $(<0.1)$ for all factors chosen, yet all had statistically significant effects $(P<0.05)$. Given the noticeable increase in OM from March 2010 onwards, additional regression analysis was carried out using mean and maximum monthly water temperatures (both for the same and previous month). Maximum temperature of the previous month showed a weak, yet statistically significant relationship $\left(R^{2}=0.1, P<0.001\right)$; other temperature relationships showed even lower $R^{2}$ values, though were statistically significant in all cases $(P<0.05)$.

\section{Discussion}

This study of sedimentation over the course of one year clearly showed that IOM and OM sedimentation are governed by different environmental factors in this highly sheltered, semi-enclosed bay and are therefore not tightly coupled. IOM sedimentation was influenced by weather and tidal factors and IOM was predominantly imported from outside the Lough. This was evidenced by IOM sedimentation rates being highest near to the Lough entrance and decreasing to lowest levels in the North Basin. Amongst the environmental factors considered, wind speed of the previous month had the strongest influence on IOM, probably because resuspension of sediments in neighbouring coastal areas (caused by strong wind and wave action) takes some time to fully affect the sheltered Lough via Barloge Creek and the Rapids. Other potential sources of suspended particles such as dredging activity and river discharge can be excluded in this study as no dredging has taken place anywhere near the Lough entrance, and no rivers discharge into the Lough; the nearest river discharges into the Atlantic to the west of Baltimore, about $6 \mathrm{~km}$ west of Lough Hyne. Strong SW winds are regular occurrence in SW Ireland and coastal areas are exposed to wave action and surge. However, the Lough itself is highly sheltered due to the semi-enclosed nature of the Lough and surrounding hills. Waves rarely exceed $1 \mathrm{~m}$ in amplitude even during strong storms [12]. Of the four tidal regimes, spring inflow had the highest influence on IOM sedimentation, which supports the hypothesis that sediments were brought in from the outside and deposited near the entrance in the South Basin where flow is fastest (of all sites inside the Lough). Reduction in current speed leads to sedimentation of inorganic matter, heaviest sediments fall out first, while finer particles remain in the water column for longer [6]. Additionally, if sediments are brought in at one point only, as appears to be the case with the Lough entrance, sedimentation will naturally decline with distance from point of entry as the water body loses sediments along the way.

In pairwise comparisons of sedimentation rates at each site it was shown that IOM sedimentation rate at Whirlpool was significantly different from that at all other sites. These findings may be explained by the gradual reduction in flow rate with increasing distance from the Rapids causing progressive loss of sediments from the water column. Sites closest to each other showed IOM sedimentation rates that did not differ significantly, probably as a consequence of the sampling points being close together and the relationship between IOM sedimentation rate and distance from the Rapids already noted.

In contrast to IOM, none of the abiotic environmental factors tested had a strong influence on OM sedimentation individually. This suggests that variations in OM sedimentation rates are driven by biotic factors that were not measured in this study, or that a combination of abiotic factors influences settlement. OM is made up of several different components including: faecal material from nekton and zooplankton, dead and dying phytoplankton and zooplankton (made up of mero- and holoplankton), resuspended organic material from sediments, plus debris derived from dislodged intertidal flora, and fauna from the exposed shores of nearby coastal waters. For example, high winds can cause winddriven turbulence, which promotes re-suspension of organic matter $[6,15]$ and dislodgement of intertidal flora and fauna. This organic material, brought into the Lough during the winter months, may provide a valuable food subsidy for benthic animals that therefore depend on productivity from elsewhere. Nutrient availability, plus rising light levels and temperatures influence phytoplankton growth in spring in temperate seas, causing spring blooms. Such blooms in turn 
lead to increased OM sedimentation [16, 17]. Zooplankton biomass increases with phytoplankton blooms and causes the production of further OM sedimentation either due to the animals' faecal pellets, their moulted exoskeletons (in the case of crustaceans), or because of death. In addition, benthic marine animals release their meroplanktonic larvae in the summer and these also cause increases of $\mathrm{OM}$ sedimentation in the summer, due either to dead larvae or faecal pellets. A deferred high OM sedimentation may be caused by blooms of plankton at different time intervals. Sedimentation rates (IOM and OM together) were lower in Bell and Barnes' study [12] than the present study and OM peaked in April (data from all sites taken together), not during the winter months. As in this study they also found the lowest sedimentation (both $\mathrm{OM}$ and IOM) in the North Basin and a positive relationship between sedimentation and wind speed. By taking OM data from all sites together they were not able to see if $\mathrm{OM}$ was produced inside or brought in from the outside of the Lough. In the present study it was possible to hypothesise where OM was coming from at different stages of the study period. Previous studies on both, phyto- and zooplankton in Lough Hyne $[18,19]$, have shown that both components of the plankton community are produced inside Lough Hyne but that some are also brought in from the outside. Nutrients have been shown to be brought in from the outside, causing increased occurrences of red tides even in the winter months, and year-round high levels of nutrients $[10,20]$. In the present study it was shown that Lough Hyne may act as a sink for IOM from the outside and that nutrients may cause increased rates of phytoplankton blooms due to the semi-enclosed nature of the Lough.

Our study highlights the importance of understanding how coastal bays interact with their adjacent seas, particularly when such basins are considered for designation as marine reserves. Policies need to involve the cleanup of pollution, avoidance of eutrophication, and limitations on permits for extractive activities in the areas neighbouring such enclosed bays. Further studies of the behaviour of separate components of the organic matter fraction are needed, as understanding what influences these components have will be valuable in understanding how these systems work internally and how they are connected to the wider ocean system. Lough Hyne is a useful model area for future studies as it is a designated marine reserve, is easily accessible, and allows observations on a confined body of water that shows marked variation in physical processes such as flow rates across a relatively short distance. Sedimentation data collected here can be used as baseline data for studies in systems where confounding factors such as differences in water chemistry or planktonic communities are encountered, or those experiencing anthropogenic disturbances.

\section{Acknowledgments}

The authors wish to thank Patrick Graham and Declan O' Donnell from the National Parks and Wildlife Service of Ireland for permission to conduct this work in Lough Hyne Marine Reserve. One of the authors (S. Broszeit) acknowledges the support of the Crawford Hayes Ph.D. studentship of University College Cork. The authors would like to thank two anonymous referees for improving the manuscript. No financial relations exist between the authors and the commercial identities mentioned in this study.

\section{References}

[1] P. A. Quijón, M. C. Kelly, and P. V. R. Snelgrove, "The role of sinking phytodetritus in structuring shallow-water benthic communities," Journal of Experimental Marine Biology and Ecology, vol. 366, no. 1-2, pp. 134-145, 2008.

[2] U. Riebesell, "Comparison of sinking and sedimentation rate measurements in a diatom winter/spring bloom," Marine Ecology Progress Series, vol. 54, pp. 109-119, 1989.

[3] T. Pearson and R. Rosenberg, "Macrobenthic succession in relation to organic enrichment and pollution of the marine environment," Oceanography Marine Biology Annual Revue, vol. 16, pp. 229-311, 1978.

[4] C. Heip, "Eutrophication and zoobenthos dynamics," Ophelia, vol. 41, pp. 113-136, 1995.

[5] R. J. Diaz and R. Rosenberg, "Marine benthic hypoxia: a review of its ecological effects and the behavioural responses of benthic macrofauna," Oceanography and Marine Biology, vol. 33, pp. 245-303, 1995.

[6] J. S. Gray and M. Elliott, Ecology of Marine Sediments, from Science to Management, Oxford University Press, Oxford, UK, 2009.

[7] R. Bassindale, F. J. Ebling, J. A. Kitching, and R. D. Purchon, "The ecology of the lough ine rapids with special reference to water currents," Journal of Ecology, vol. 36, pp. 305-322.

[8] R. McAllen, J. Davenport, K. Bredendieck, and D. Dunne, "Seasonal structuring of a benthic community exposed to regular hypoxic events," Journal of Experimental Marine Biology and Ecology, vol. 368, no. 1, pp. 67-74, 2009.

[9] R. Bassindale, E. Davenport, F. J. Ebling, J. A. Kitching, M. A. Sleigh, and J. F. Sloane, "The ecology of the lough ine rapids with special reference to water currents. VI. Effects of the rapids on the hydrography of the South Basin," Journal of Ecology, vol. 45, pp. 879-900, 1957.

[10] M. Jessopp, R. McAllen, J. O. O’Halloran, and T. Kelly, "Nutrient and Ecosystem Dynamics in Ireland's only marine nature reserve (NEIDIN)," STRIVE Report 66, Environmental Protection Agency, 2011.

[11] K. A. Rawlinson, J. Davenport, and D. K. A. Barnes, “Temporal variation in diversity and community structure of a semiisolated neuston community," Biology and Environment, vol. 105, no. 2, pp. 107-122, 2005.

[12] J. J. Bell and D. K. A. Barnes, "The relationship between sedimentation, flow rates, depth and time at Lough Hyne Marine Reserve," Irish Naturalist Journal, vol. 27, pp. 106-116, 2002.

[13] L. Håkanson, S. Floderus, and M. Wallin, "Sediment trap assemblages-a methodological description," Hydrobiologia, vol. 176-177, no. 1, pp. 481-490, 1989.

[14] S. G. Wakeham, J. I. Hedges, C. Lee, and T. K. Pease, "Effects of poisons and preservatives on the composition of organic matter in a sediment trap experiment," Journal of Marine Research, vol. 51, no. 3, pp. 669-696, 1993.

[15] J. Davenport, T. V. Moloney, and J. Kelly, "Common sea anemones Actinia equina are predominantly sessile intertidal scavengers," Marine Ecology Progress Series, vol. 430, pp. 147155, 2011. 
[16] V. Smetacek, K. von Bröckel, B. Zeitzschel, and W. Zenk, "Sedimentation of particulate matter during a phytoplankton spring bloom in relation to the hydrographical regime," Marine Biology, vol. 47, no. 3, pp. 211-226, 1978.

[17] V. Smetacek, "Annual cycle of sedimentation in relation to plankton ecology in western Kiel Bight," Ophelia, Marine Biological Laboratory Supplement, vol. 1, pp. 65-76, 1980.

[18] K. A. Rawlinson, J. Davenport, and D. K. A. Barnes, “Tidal exchange of zooplankton between Lough Hyne and the adjacent coast," Estuarine, Coastal and Shelf Science, vol. 62, no. 1-2, pp. 205-215, 2005.

[19] M. J. Jessopp and R. J. McAllen, "Go with the flow: tidal import and export of larvae from semi-enclosed bays," Hydrobiologia, vol. 606, no. 1, pp. 81-92, 2008.

[20] M. P. Johnson and M. J. Costello, "Local and external components of the summertime plankton community in Lough Hyne, Ireland a stratified marine inlet," Journal of Plankton Research, vol. 24, no. 12, pp. 1305-1315, 2002. 

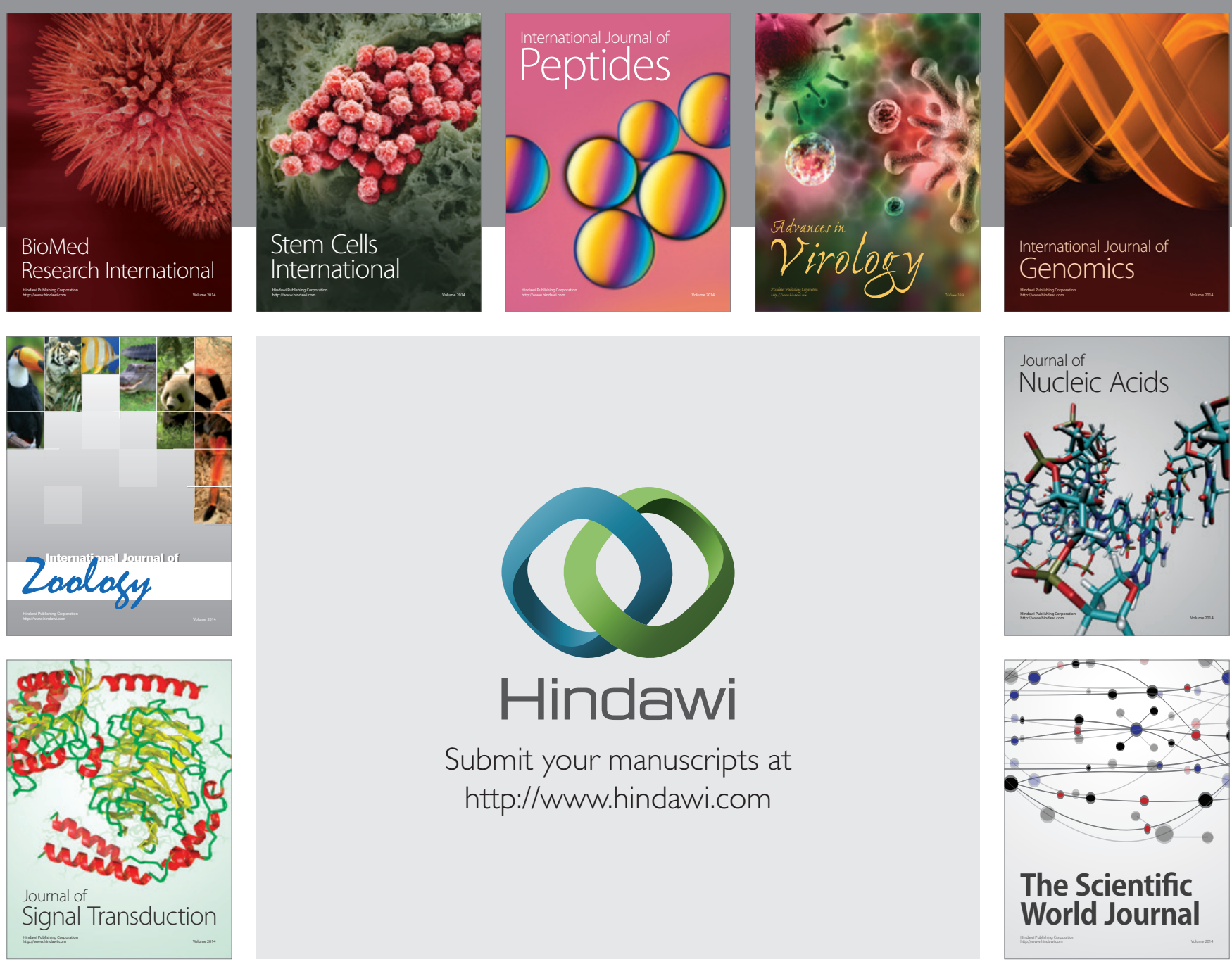

Submit your manuscripts at

http://www.hindawi.com
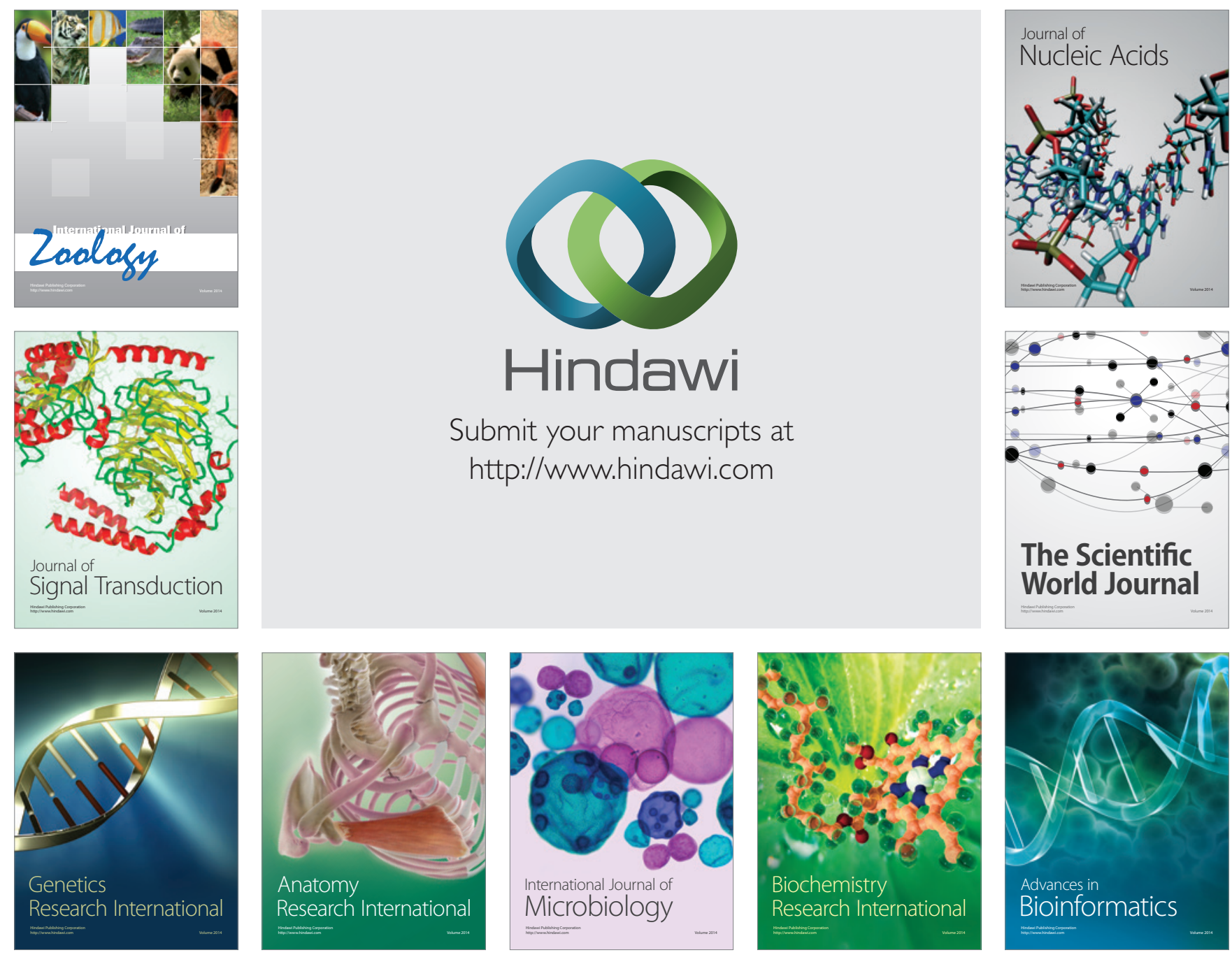

The Scientific World Journal
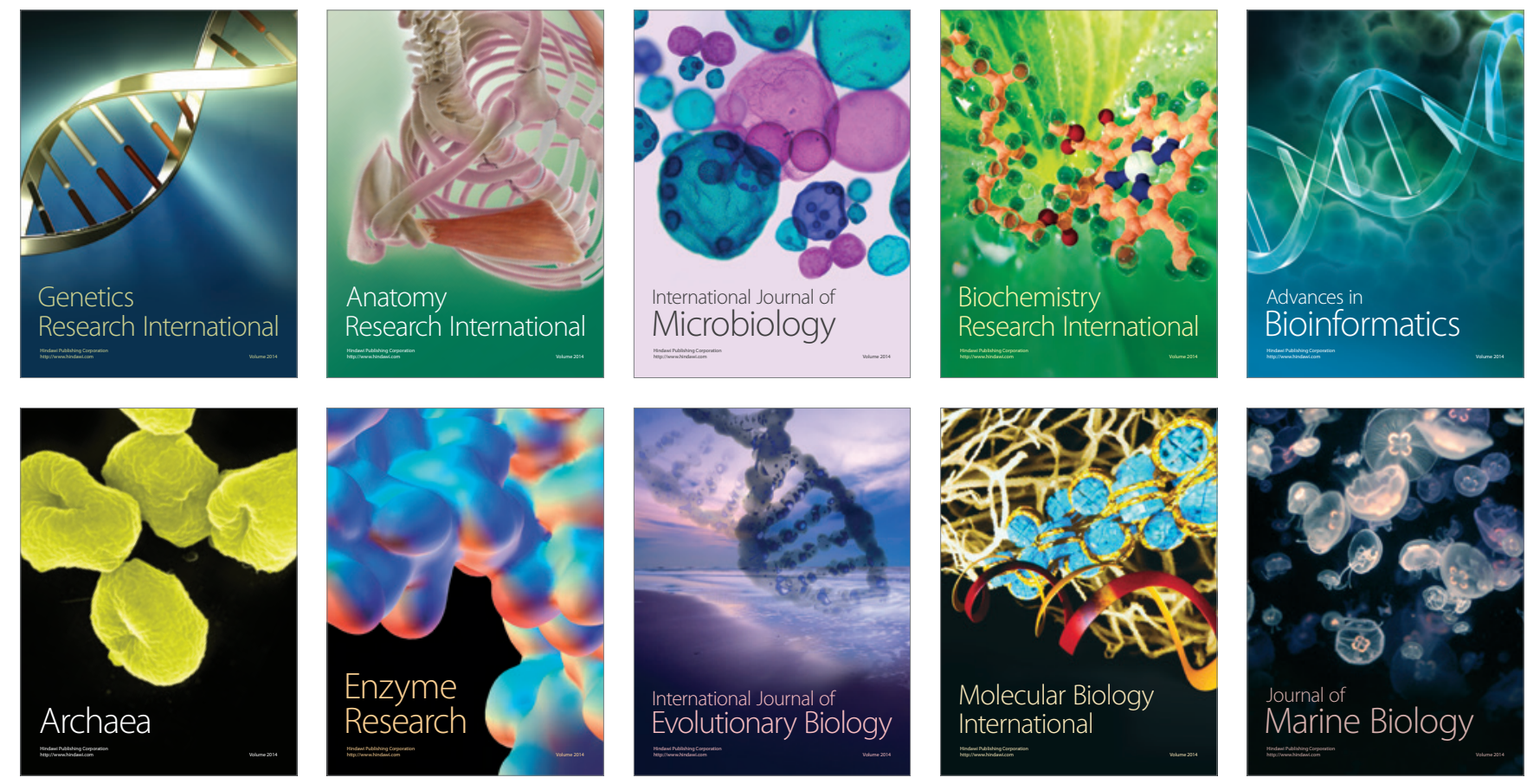